\title{
The Spatial Characteristics of Homes as Private Domains that May Promote Youth Offending
}

\author{
Thozama Mandisa Lutya
}

\author{
Department of Social Work and Criminology, Faculty of Humanities, University of Pretoria, Hatfield Campus, \\ Cnr Lynwood and Roper Streets, Pretoria, 0002, South Africa
}

\begin{abstract}
This a review analysis concerned with describing the spatial characteristics of homes as private domains that may promote youth offending. The goal of this paper is to explicate such characteristics and relate them to the development of a young criminal personality. The main point is that the manner in which homes are structured and family processes are conducted could give children many opportunities to learn criminal behaviour without interruption. The geographical themes of space, time and culture are used to explicate the characteristics of the home as a private space. Research results from reviewed articles have given this paper three structured sections. The first session briefly defines and describes the home as a private space. Section 2 critically discusses the hidden dimensions of the home as a private space. The family is identified as a site of authentic experience, ownership and secrecy, commitment and an obligation to shared values, as well as voluntary compassion. The home is shown to be a territory of respect and recognition, but it is also argued that, under particular circumstances, these characteristics of the home could influence or allow children to learn criminal behaviour. The last section of the paper focuses on factors in the home that influence children to replicate negative parental behaviour, although it is acknowledged that most parents do not consciously wish their children to learn non-conforming behaviour in their homes, and that not all children exposed to concealed negative home characteristics will commit a crime. It is suggested that crime prevention efforts should start with the interrogation and mediation of home and family characteristics that could influence children to learn criminal behaviour.
\end{abstract}

Keywords: Home, private domain/space, youth offending, parental behaviour, learning, home and family characteristics.

\section{INTRODUCTION}

Often one hears people saying: 'I offered this child a home and now this child does not want to listen to me.' Then you see people nodding in agreement with this statement, ignoring the possibility that the spatial modes of interaction in that home may have undermined the likelihood of this child's behaving lawfully in the future. When a child is a member of a home with parenting adults, people usually automatically assume that this home contains authority figures that willingly care for and nurture the child. Another long-standing (mis)perception is that homes offer security, love, and care. However, these very characteristics may be contrary to the development of a healthy personality. This paper seeks to identify characteristics, which turn homes into underlying structures within which some parents, or guardians may (knowingly or inadvertently) nurture youth criminal personalities. It analyses and describes the features of children's homes as private spaces that might provide opportunities for children to learn criminal behaviour.

Homes provide a shared consumption of learning of which children become the primary beneficiaries (or, in some cases, victims). The shaping of potentially

*Address corresponding to this author at the Department of Social Work and Criminology, Faculty of Humanities, University of Pretoria, Hatfield Campus, Cnr Lynwood and Roper Streets, Pretoria, 0002, South Africa; Tel: 012420 5906; Fax: 012420 2093; E-mail: Thozama.lutya@up.ac.za criminal identities is based on the quality of this learning, offered within the confines of the home in which a person's early childhood years are spent. Massey (2004:5) maintains that identities are relational, because they are constructed in and through relations during processes of interaction. The power of social relations facilitates a capacity to bring such lessons, through time and space, into everyday practice (Pred, 1981:31). The migration of a criminal space from a local (domestic) space to the global space occurs through a process of 'ongoing productions' (Massey, 2004:5).

Ironically, most home occupants tend to be complacent with regard to the artefacts that allow the private space of the home to produce criminal behaviour, whereas they are often vocal concerning crimes committed by strangers, forgetting that these strangers are themselves occupants of homes elsewhere. The South African crime statistics and victimization surveys from non-governmental organisations inform us annually about the increase in the number of contact crimes (occurring between known persons); yet South Africans are concerned primarily about crimes occurring in the public space. What makes people more open and clear-sighted regarding crime-inducing factors in public spaces than they are regarding issues in the home that may induce law breaking? 
Children learn criminal behaviour from the local home space and express what they have learnt in the global space (the playground and the wider world). The home is the centre where children learn these activities, because it does not offer constraints but opportunities for action, forming the basis for what children know about the world and the materials for changing (Peet 1998:151). Moreover, in cases where parents and adults actively and deliberately use children to commit crime and compliment the children based on the violence that the children exert during the commission of such crime, the learning is even more deeply entrenched. Consequently, the intensity of the learning in such local spaces as the home might make it impossible for children to fight off the lessons inculcated in them by adults whose parenting is harmful. Peet (1998:154) points out that social agents internalize dominant modes of thought and experience that are inherent in their physical and social worlds, and they might order such practices across space and time. Thus, children might internalize improper conduct by parents by means of 'a mental monitoring of the flow of social life meaning watching and learning from actions' (Peet 1998:154).

\section{DEFINITION OF THE HOME AS A 'PRIVATE SPACE'}

\section{What is a Home?}

A home may be defined as a domestic space where social patterns are reproduced more or less free from outright control by outside forces such as the State (Drummond 2000:2379). It is a popular conception that a private space is one free from outside impingements and obligations. However, feminists have pointed out that such a private space may become a site of oppression when one member infringes upon the rights of other members (Drummond 2000:2379). Hence, privacy is important, but critical analysis should balance it against competing interests, because protecting one person's privacy might lead to restraints of the freedoms of another (Niessenbaum, 1998:559).

\section{The Home as a Private Space}

The meaning of the term 'home' depends on the operational functionality of the space within which an individual resides. It is important to note that the feelings attached to this definable space stabilize its meaning. Lucas and Purkayastha (2007:244) argue that a home is a sheltered environment which is territorially based on identity and belonging. The home is associated with a space where identity might find its structural shape. Lucas and Purkayastha (2007:244) also suggest that the home embodies specific feelings of safety, familiarity, comfort and love. In addition, they observe that it is an indication of success where people's social standing can be measured with regard to their income and wealth. The contents found in each home are often symbolic of the income generated by that household.

Similarly, Massey (2004:7) explains that socializing agents assign essential characters within their household that distinguish them from other families: the manner in which they discipline children and interact closely. Consequently, through their affiliation in the home environment before outside social interaction occurs or resumes, individuals such as children tend to use the knowledge they have accumulated at home. Massey (2004:7) also notes that identity is then created through place, and a child would be oriented to the space and place in which the child resides before claiming knowledge from other spaces. It is likely that children identify more with the conflict resolution measures used by parents than with the actions of others that they observe in the public space. Nevertheless, it is possible that some children who have observed traumatic events do not replicate their first-hand experiences of trauma - children who do not identify with primary caregivers may not see the need to copy or model the behaviours of such figures (Cunningham and Baker 2004).

The private domain has real effects within the social world, because it shapes the attitudes and behaviour of its occupants (Blomley 2005:.284). It provides an arena in which human beings meet or fail to meet their moral obligations, an area in which people develop their own inviolable personality (Cater 2004). The private domain allows for the development of a criminal personality to occur unabated, because in it children are blocked from interacting with the outside world, which could motivate them to disregard criminality (Schwanen 2007). Therefore, in order to make sense of public social forms and processes, it is important to investigate the issues of identity role socialization and especially internalization (Bailey 2000:386) related to the home. Children learn their parents' behavioural modes even when the parenting transmitted to them is treacherous and/or detrimental to their mental stability. Most parents do not tolerate outside interference regarding their parenting, for example, if an outsider attempts to teach a child manners that are contrary to a biological parent's belief, conflict may arise. 
It is possible to view a home as a safe haven until an outsider identifies risk factors that could create unsafety (Cowburn and Dominelli 2001:411). Nevertheless, whether spaces are private or public, they remain basic arrangements of social existence (Reingardiene 2003:354). Children might find it difficult to conceive an objective world different from their home, even when they enter diverse settings. Society produces human beings, and their reality is informed by the space within which they construct their social knowledge (Love 1996:156). If one accepts this argument, it follows that what children feel and think is derived from their individual social experiences, which includes those in the private space of the home. The singularity of being human is being alone with constant experience in thought and feeling separate and distinct from others (Bailey 2000:390).

People generally do not expect children to engage in criminal activities when they reside with primary caregivers who may own and maintain the home. Milligan, Atkinson, Skinner and Wiles (2007:138) have observed that where homes are concerned, people often ask morally connected questions in relation to the construction of a home as good, focusing on the presence of what are assumed to be responsible caregivers rather than on the context within which caregiving is provided. Milligan et al. (2007) look specifically at the care of vulnerable groups, which include the physically challenged, but it should be noted that children are often brought up in a space that society conflates with care giving, even where none may occur. The broad view of homes as places of care might be misleading, especially considering that children may well learn lessons that promote criminal behaviour within the confines of the home.

It is not easy for the public to be alert to lessons leading to criminal behaviours learned by children at home, because such learning occurs in private spaces. It is only once those who facilitate the perpetration of crime or the criminals are caught that such crimes become a public matter. For example, abuse between family members may remain hidden until one partner or victim breaks the chains of silence and reports the crime to the criminal justice authorities. Preceding the involvement of the criminal justice system, being a victim of violence at the hands of an intimate partner is shrouded in secrecy. Both partners may request privacy, because an act of violence may warrant legal liability, which might cause substantial public condemnation and personal damage (Strahilevitz 2005:42). Persons who have a proclivity to behave criminally in private but condemn wrongdoing in public often maintain a dual character - in private, they let their criminal selves out, but they maintain a dignified stance in public. The private space offers a private arena in which most individuals may simply be their private selves, and people are unrestrained (Bailey 2000:389).

\section{CHARACTERISTICS OF THE HOME AS A PRIVATE DOMAIN}

\section{The Family as a Site of Authentic Experience}

It is within the privacy of homes with families that children undergo intellectual, spiritual and personality development; in the end, these lessons enable them to separate right from wrong. This process of the reception of moral direction trains them to express feelings that may be conceived to be either good or bad. The construction of ideas as a social process can shape, crucially and fundamentally, what each child knows. Once opportunities arise, this knowledge should be readily available for use. It is possible that a child will not regard particular actions as unacceptable, because these actions are unmitigated and uncriticised when the child learns these lessons. In this regard, Schwanen (2007:11) cites Hägerstrand (1974, 1984, 1988), who argues as follows:

The manner in which children's lessons in the private domain are ordered is in accordance with the spacing and timing of bodies, artefacts and other items as parts of the landscape in a continuous attempt to protect a project (child's learning) from the intervention of unwanted influences (outsiders or strangers). For parents, it is a double challenge of keeping favourable things and events within reach and unfavourable ones out of the immediate environment through a variety of interrelated strategies.

In this respect, children might participate in a violent project without necessarily recognising its devastating consequences, and normalizing it instead. Therefore, children's experience remains authentically inscribed in their mental modes. The space that families share should therefore be seen not only as a geographical space, but also as a collated production of social practices whose individual use is based on social power (Koskela, 1999:112; Koskela and Pain 2000:275). At a young age (below 18), some children 
might possess the financial and mental power to move away from such lessons, but very few do.

\section{Ownership and Secrecy}

Homeowners design their homes uniquely and control them in accordance with their budgets. In middle-class suburbs, one may find, for example, homes surrounded with huge fences and security apparatuses as an indication of the value that the owners attach to their property. The significant symbols that define the design of most homes are intended to deter strangers from entering. It seems that there is a territorial claim that this space is owned, and that no interference will be tolerated: everything within such boundaries is owned (Blomley 2005). That which is inside is usually shielded from the prying eye of the public. By contrast, homes in lower class environments may lie bare, uncovered and vulnerable to intrusion from outside influences. Owners always exercise a degree of dominion and control, in the sense that if an owner sets his/her fence beyond the boundary line and trespasses onto another's property, he/she may expect to be encroached upon and the owner then has to act to defend his/her boundaries (Blomley 2005:284). This invisible character of the home makes it more private and more likely to conceal crimes such as violence against vulnerable members, namely women and children. According to Koskela (1999:118), the invisible character of the home is reciprocally conditioned as an important context for the exercise of power.

\section{Commitment and Obligation to Shared Values}

It is possible for criminal behaviour to be transmitted unabated between generations in the home, and such behaviour may become an essential or core valuedriving survival within a home. Activities learnt at home can only be seen as situated activities and should be distinguished from theoretical learning, attained from formal schooling, which might be decontextualized (Love 1996:155). For example, it appears that in some South African homes, surviving on the proceeds of crime is seen as a means to meet financial and economic needs. According to Moor (1997:29), as repulsive as this behaviour may be, it might be acquired, learned, and repeated by the young, then might become a core value across generations. Moor suggests that the sustenance of any core values necessitates instrumental and intrinsic support. This implies that for a child to acquire and transmit this behaviour, privacy is of the utmost importance. Some cultures require protection from strangers who may have goals aimed at destroying the development of core values (Moor 1997:29).

Often private spaces such as the home contain people with shared values and norms that are familiar only to them. Although a child's mother and father may not have been reared in the same household, and may originate from different backgrounds, it is clear that when they gather in the space of their shared home, they formulate norms and values they could share for a prolonged time. To illustrate this point further, in schools, when the bell rings, the learners ascend to the assembly hall or classrooms at once, and failure to do so might result in severe punishment. In correctional centres, the inmates and correctional officials follow the rules stipulated by the national government. In most homes, the family members are expected to converge at the dining table at specified meal times. Behaviours contradicting structural norms and values may warrant punishment, and some such punishments might steer children towards eventually using violence as a form of discipline on their own children.

\section{Voluntary Compassion}

A home context is assumed to be a space where family members congregate. Bailey (2000:391) points out that in order to allow voluntary compassion to be exercised, some families might automatically order the members to hinder the expression of aggressive emotions in favour of the nurturance of others. The quality of this nurturance might be seen in the manner in which family members relate to one another in public. Often, one hears people who share a common space say: 'It is my mother/teacher/manager/wife/ husband/sister/father/brother, therefore I have to do it/listen/go etc.' Moreover, one often hears parents chastising their offspring when the children display improper behaviour, especially when there are visitors present. Sadly, parental reprimands may not necessarily be motivated by a sense of exercising discipline but may be prompted by the embarrassment arising from the child's unruly behaviour (Johnson 1992).

Most private spaces are associated with people's right to intimacy and individuality, which deserve to be respected by others (Hasanbegovic 1999:6). It is possible to argue that the assumption of the existence of voluntary compassion might influence some people to expect homes to be havens of peace and harmony. Nevertheless, it might also be where most children learn how to hate, resent, despise and express 
violence - attributes that contribute to criminal offences by young people. The space occupied by children and the culture of some homes offer vital lessons, which are often expressed by deviant behaviour at first, and by criminal acts at a later stage. However, it must be acknowledged that the home might not be the only private space that nurtures lawless behaviour by children.

\section{The Home as a Territory of Respect and Recognition}

The home is an area where inhabitants' erratic behaviour may be allowed to prevail unabated because those in the household who witness this behaviour recognize and respect the individuality and privacy of this person. Private spaces are not necessarily bad, but it is likely that in these spaces most wrongdoing may not be conceptualized as such, or may go unnoticed. The risk is that in honouring privacy an undesirable 'anything goes' atmosphere is created, which includes the personal freedom to break the law or social conventions (Johnson 1992:12).

An example that illustrates this dichotomy is a 'good man' who is the head of the household, and who is simultaneously a 'bad man' who uses violence towards his family. Such violent acts may remain concealed due to the enormous amount of respect associated with this man's position within the family. By contrast, intruders who might attack a family unexpectedly are seen as 'bad men'. This dichotomy allows criminal behaviour in private spaces to occur unrestricted, as long as it is a person known to the victim that engages in this behaviour. Cowburn and Dominelli (2001:12) are of the opinion that this belief is generated from the argument that children would be happy in families which consist of a mother and a father. The idealisation of the nuclear family structure has imprinted the notion that this type of family is better. However, there are many other kinds of non-nuclear households, such as single parent households, child-headed households, extended family households and sheltered households that do not share the same conventions and norms. Children can consume criminally oriented beliefs that create an impression that crime is an acceptable way to achieve personal goals in both nuclear and non-nuclear households.

Another dichotomous relationship between the private and the public is generated by a fear of crime. Most people would attest to the fear of walking alone in the night or driving into the city after midnight. Spaces that are shared with strangers are likely to be viewed with suspicion and fear (Pain 2001:899). However, this is generally not the case with private spaces, in which some behaviours that the law might consider criminal if they occurred in the public space are perceived as 'normal' (Cowburn and Dominelli 2001). It may be argued that the same people who would feel threatened in the public space may feel safe in the confines of their own homes. Cowburn and Dominelli (2001) point out that the home continues to be perceived as a safe haven whilst communities are seen as dangerous.

A child is likely to develop situated knowing through the process of adultism, which entails that adult family members become the most respected and feared figures in the child's life (Lohan 2000). The performance of adultism allows adults to exercise authority over their children, which may result in children's keeping secret any victimization by their parents. According to Lohan (2000:110), situated knowing is postulated on the basis that all knowledge is produced somewhere by somebody and that knowing must also be placed in the context of interrelationships between the knower and the known. In the context of inter-personal relationships, children learn particular behaviours that can be defined as criminal by the criminal justice authorities. In the process of learning such behaviours, children may not be aware that they are consuming criminal behaviours.

The use of violence to resolve conflicting situations may be one of those behaviours that are taken for granted and that regularly occur in private spaces without reprimand, but that criminal justice agencies would punish if a stranger engaged in them. Essentially their learning is aligned to the beliefs, actions, values, and processes observed from feared adults. It is possible that some children do negotiate their socialization with their parents. However, where young offending is concerned, there is a strong likelihood that authoritative behaviour and unquestioned authority is implemented through aggression. Children learn from parents during the process of parent-child interaction and tend not to hold parents accountable for victimization or to question it.

Criminal behaviour by young persons in public illustrates the type, the quality and the basis of these young persons' situated knowledge of such behaviour learnt in a private space (Lohan 2000). A child is likely to have consumed this knowledge tacitly during the process of interaction with the other occupants of the 
child's private space (the home). At the time, the parents may not have foreseen the consequences of what the child witnesses and observes, or may not have recognised the importance of this witnessing. Where adults engage in behaviour that is likely to lead children to turn into criminals, displayed behaviour is likely to lead to a trail of thought that argues that violence is the answer to conflict. Some parents may simply assume that as long as children have a roof over their heads and parents to look after them in some form, the children are safe, and/or that children should know that some private home learning processes are not meant to be replicated in public.

Private spaces may offer the occupants of such spaces plenty of room to witness, model, and repeat observable behaviours until they become habitual. For example, children learn by becoming aware of others, interpret behaviour, and converse with gestures (Johnson 1992:12). During this time, parents might judge the appropriateness of this behaviour in comparison to the acceptable family modes of behaviour. Accordingly, parents may punish a child immediately if the child's behaviour contradicts family values, or may ignore it if the guardian does not care.

\section{WHY DO CHILDREN REPLICATE PARENTAL BEHAVIOUR?}

In order to understand the replication of parental behaviour by children, it is necessary to understand the negative impact of family or home-related risk factors and criminogenic factors. Family or home-related risk factors include a lack of financial resources, inept parenting, child abuse and inter-parental violence (Maree 2008). By contrast, criminogenic risk factors are associated with criminal activities: it could be parental drug dealing and abuse, or surviving on criminal proceeds (Maree 2008). Family and home-related factors are prevalent in most homes, regardless of the existence of criminogenic risk factors such as interparental violence. Some children may break the cycle of financial inadequacy by getting an education that will allow them to compete in the labour market system, but it might be difficult for certain children to break the cycle of violence later in life. Witnessing parents dealing in drugs or surviving on crime proceeds may teach children that criminal activities yield financial incentives. Children may construe child abuse as an appropriate manner of disciplining the children. It is important to note that children learn lessons in criminal behaviour through their interpretations and modelling of behaviours performed by their parents. Inter-parental violence can be more expressive and easy to learn than peaceful ways of existence. Violence is immediate and spontaneously expressed. It may not be suppressed in homes that may have been using it for a long time. It could be difficult for violent homes and family members to suddenly refrain from violence and resort to peaceful ways of existence.

People who may have experienced violence in similar spatial domains do, however, develop different personalities. The spatial nurturance of criminal behaviour requires any writer to clarify the manner in which children explicate crime lessons in order to avoid othering persons who engage in unlawful behaviour. In this regard, Massey (1999) stresses the need to think historically by distinguishing between those processes that are timeless and those that are time-bound. Timeless processes have a tendency to develop an open future. That means that when they are left unmitigated, experiences of violence have a tendency to reshape and structure a later stage of a child's development. However, Massey (1999) observes that behaviour that is learned may not be expressed in the same way in which it was learned, because things somehow change in themselves. In order to explain this change, temporality/time has to be conceived of as a product of interactions and interrelations. A tricky point relating to this equation is whether this temporality is as dynamic in physics as it is in children's personalities. Do children forgo lessons learned, modelled and expressed at play once they reach a stage of dating, friendship and marriage? One might argue that such lessons are timeless, unless mitigating factors are applied. Massey (1999: 268) argues as follows:

Time cannot hold itself in its bootstrap and change; it ought to be influenced by interrelationality. Time needs space in order to get itself going. Time and space are interlinked. For time to be considered as open, space could be imagined as the sphere of existence of multiplicity, a space in which distinct stories meet up, conflict, or cooperate.

The interpretation and internalization of violence experienced during childhood depends on the environment within which that violence occurs. Cater (2004:43-50) lists three contexts that might influence the internalisation and replication of violence. Firstly, for violence to be internalized, the child has to witness violence as an individual. The self allows for a process 
of consuming theatrical actions, which then manifest in mental codes in a whirlwind of growth, change and revision throughout life as an individual continues to interact with others. Violence becomes meaningful and significant as a child progresses through life if there are only limited spatial opportunities for the child to experience and learn differently. Where children witness primarily violence, but are also able to witness examples of peaceful alternatives in a secondary context, they may be able to make use of the chance to interrogate their home situations and assimilate communal content on peace as an alternative.

Secondly, children's first personal connections are generally with significant others, which could influence the types of friendship they select later in life (Cater 2004). In this regard, Farrington and Smith (2004) have shown that children reared by inept, violent and poverty-stricken parents are likely to select partners with similar characteristics, thus enabling an intergenerational cycle of violence. However, a child whose cognitive faculties are stronger than his/her emotional make-up may negotiate the future differently, despite such modelling.

Thirdly, in respect of the processing of violence by the self and becoming acquainted with it early in life in inappropriate role models, when the same inappropriate behavioural expressions are found in society and the media consumed by a child, there is a strong likelihood that this model of behaviour will gain strength and will have a higher impact on the child's personality. According to Cater (2007), children would be attracted to social images that resemble the behaviour they have seen modelled by their parents; moreover, children would use these images to formulate a single strategy called a generalised other. Engaging in criminally violent behaviour would thus depend on the behavioural expressions displayed by a child's significant and generalised others and the cognitive and emotional faculties of the child concerned. The home therefore becomes the centre where a child is learning regarding such lawless behaviour starts.

Lastly another dependent variable to the replication of violent behaviour by offspring: the roles and expectations of fighting parents might trigger children's emotional faculties. Cunningham and Baker (2004:8) point out descriptively that of inter-parental violence might force children to undertake various roles amidst the ferocious parental rows. The child may take on the role of caretaker, mother's confidant (e), abuser's confidant (e), abuser's assistant, perfect child, referee and scapegoat. The role a child adopts whilst viewing live parental conflict may influence the type of violence he/she will pursue to shape his/her personality. The fact that children are more likely to look at the problem holistically according to such roles, versus the violence itself, might influence the replication or modelling of parental behaviour. According to Cunningham and Baker (2004:34), a story reported by Mullender et al. (2002:9-96) illustrates how carefully children as witnesses note the spatial characteristics of interparental violence. A child in Mullender et al.'s study illustrated the background events to have restarted from the sitting positions of the parents during the triggering event, the objects used to create a bruise and heal it, until the authorities got involved. The narrative logical sequence of the story suggests that it is possible for aspects of an event that seem trivial to an adult to leave an indelible mark upon the child's theatre of memory.

The replication of parental violence is made more likely by the fact that a child's father is an image of authority that symbolizes the steering of children towards conforming behaviour. It is in the execution of the father's roles rather than his biological sex from which children tend to extract behavioural maps to use in future. Contradictory behaviour, such as beating a child's mother, while at the same time telling children to follow legal norms, might create an impression that crime is something to be feared in public more than it should be feared if it is demonstrated by a significant symbol of authority in private. Cater (2004:24-25) postulates that when a child's father treats the mother as a punching bag, this behaviour may have negative repercussions, such as the development of lawless behaviour by the child. However, the manner in which a child might interpret these actions depends upon the family's use of violence-related concepts. The words a father uses when he hits the child's mother have a bearing on the replication of violent behaviour. What words might he use to exert this violent pressure? Might he say 'stupid', 'useless', 'nagging' and use all sorts of nuanced expletives that violent men might use to excuse their ill personalities by blaming others? As already stated above, children have limited residential alternatives. They may have limited choices in terms of selecting an abode. That means the child's exposure to violent images might be prolonged, with enough chance for internalisation and later replication to occur. By the time a child is exposed to alternatives to this arrangement, the understanding of conflict resolution 
has already been fixed into 'I use violence when provoked', taking into consideration the words the father uses when beating the child's mother.

The transmission of parental modes of behaviour occurs authoritatively in situations where inter-parental violence is shrouded in secrecy, and the strategic response sometimes offered by social services once this matter has been turned into their concern. In the case of a father's abusing a mother, Stanley (1996:140) has pointed out that the trappings of and invisibility associated with such a situation might make it easier for children to replicate the behaviour. The secrecy with which inter-parental violence is handled may motivate children to replicate such violence later in life.

\section{CONCLUSION}

Many analysts avoid interrogating the home: it is rarely an institution analysts wish to debate. It is regarded as a private domain. There is a social perception that what happens in private ought to remain private. Furthermore, the intimate circumstances of significant others are considered as better served when left unexamined by the prying eye of the public. However, the home, shrouded in secrecy and serving as a sheltered space that is invisible to the public, is an area where it is possible for children to learn criminal behaviours efficiently. Reingardiene (2003:359) points out that the domestic arena is a space where the accumulated pressures of public life are likely to be expressed. That means it is within this domain that particularly women are humiliated, shoved and grabbed, right under the eyes of the children. It is possible for such violent images to be consumed, unmitigated, and replicated either as a survival strategy or as a mechanism of dealing with conflict. The use of violence might bring children to the attention of criminal justice authorities, placing them at risk of serving correctional sentences. With no alternative shelter, children resort to committing to the home environment, regardless of the potentially destructive consequences to their personalities. Whether children will eventually replicate the behaviour they see in the home depends strongly on the role they take on while witnessing such violence.

The intention of this paper is not to present compelling arguments on whether children who emanated from violent backgrounds become criminal or not. The intention is to illustrate the influential characteristics of the space called home on children through historical time. This paper recommends that crime prevention efforts should mediate lessons learnt from the home when planning and implementing youth offender reduction strategies. The home should not be romanticised. All children experience challenges within their homes, and the manner in which adult supervisors guide them to synthesize such experiences may cultivate behaviour that is either non-offending or involves wrongdoing.

\section{REFERENCES}

Bailey, Joe. 2000. 'Some meanings of "the private" in sociological thought', Sociology 4(3): 381-401.

Blomley, Nicholas. 2005. 'Flowers in the bathtub: boundary crossings at the public-private', Geoforum 36: 281-296. http://dx.doi.org/10.1016/j.geoforum.2004.08.005

Cater, Asa, K. 2004. 'Negotiating normality and deviation - father's violence against mother from children's perspective', Orebro University: Orebro

Cowburn, Malcom and Dominelli, Lena. 2001. 'Masking hegemonic masculinity: reconstructing the paedophile as dangerous stranger', British Journal of Social Work 31: 399-415. http://dx.doi.org/10.1093/bjsw/31.3.399

Cunningham, Alison and Baker, Linda. 2004. What about me: seeking to understand a child's view of violence in the family. Centre for Children \& Families in the Justice System of the London Family Court, London.

Drummond, Lisa. 2000. 'Street scenes: practices of public and private space in urban Vietnam', Urban Studies 37(12): 2377-2391.

http://dx.doi.org/10.1080/00420980020002850

Farrington, David, P, and Smith, Carolyn, A. 2004. 'Continuities in anti-social behaviour and parenting across three generations', Journal of Child Psychology and Psychiatry 45(2): 230-247. http://dx.doi.org/10.1111/j.1469-7610.2004.00216.x

Hasanbegovic, Claudia. 1999. 'The feminine is political: domestic violence and its similarities with torture', Canterbury: University of Kent.

Johnson, Jeffrey, L. 1992. 'A theory of the nature and value of privacy', Public Affairs Quarterly 6(3): 271-288.

Koskela, Hille. 1999. "Gendered exclusions": women's fear of violence and changing relations to space', Geografiska Annaler 81(B): 111-124.

Koskela, Hille, and Pain, Rachel. 2000. 'Revisiting fear and place: women's fear of attack and the built environment', Geoforum 31: 269-280.

http://dx.doi.org/10.1016/S0016-7185(99)00033-0

Lohan, Maria, 2000. 'Comeback public/private: (almost) all is forgiven: using feminist methodologies in researching information communication technologies', Women's Studies International Forum 23(1): 107-117. http://dx.doi.org/10.1016/S0277-5395(99)00094-1

Lave, Jean. 1996. 'Teaching as learning in practice', Mind, Culture and Activity 3(3): 149-164.

http://dx.doi.org/10.1207/s15327884mca0303 2

Lucas, Susan and Purkayastha, Bandana. 2007. "Where is home?" Here and there: transnational experiences of home among Canadian migrants in the United States', GeoJournal 68: 243-251. http://dx.doi.org/10.1007/s10708-007-9073-0

Maree, Alice. 2008. 'Criminogenic risk factors for youth offenders', in Bezuidenhout, C. and Joubert, S. (eds): Child and Youth 
Misbehaviour in South Africa: A holistic Approach. Van Schaik, Pretoria, pp. 55-91.

Massey, Deborah. 1999. 'Space-time science and the relationship between physical geography and human geography', Transactions, Institute of British Geographers NS 24: 261276.

http://dx.doi.org/10.1111/j.0020-2754.1999.00261.x

Massey, Deborah. 2004. 'Geographies of responsibility', Geografiska Annaler 86(B 1): 5-18.

Milligan, Christine, Atkinson, Sarah, Skinner, Mark and Wiles, Janine. 2007. 'Geographies of care: a commentary', New Zealand Geographer 63(2): 135-140. http://dx.doi.org/10.1111/j.1745-7939.2007.00101.x

Moor, James, H. 1997. 'Towards a theory of privacy in the information age', Computers and Society, 27(3): 27-32. http://dx.doi.org/10.1145/270858.270866

Nissenbaum, Helen. 1998. 'Protecting privacy in an information age: the problem of privacy in public', Law and Philosophy 17: 559-596.

Pain, Rachel. 2001. 'Gender, race, age and fear in the city', Urban Studies 38(5): 89-913. http://dx.doi.org/10.1080/00420980120046590
Peet, Richard. 1998. Modern geographical thought. Blackwell, Oxford.

Pred, Allan. 1981. 'Social reproduction and time- geography of everyday life', Geographica Annaler: Series B Human Geography 89(1): 5-22. http://dx.doi.org/10.2307/490994

Reingardiene, Jolanta. 2003. 'Dilemmas in private/public discourse: contexts for gender based violence against women in Lithuania', Journal of Baltic Studies 34(3): 354-368. http://dx.doi.org/10.1080/01629770300000131

Schwanen, Tim. 2007: 'Matters of interest: artefacts, spacing and timing', Geografiska Annaler 89(B 1): 9-22.

Stanley, Nicky. 1996. 'Domestic violence and child abuse: developing social work practice', Child and Family Social Work 2: 135145. http://dx.doi.org/10.1046/j.1365-2206.1997.00052.x

Strahilevitz, Lior, J. 2005. 'A social networks theory of privacy', American Law and Economics Association Annual Meeting, Paper 42.

Received on 17-10-2012

Accepted on 24-11-2012

Published on 06-12-2012

DOI: http://dx.doi.org/10.6000/1929-4409.2012.01.20

(C) 2012 Thozama Mandisa Lutya; Licensee Lifescience Global.

This is an open access article licensed under the terms of the Creative Commons Attribution Non-Commercial License (http://creativecommons.org/licenses/by-nc/3.0/) which permits unrestricted, non-commercial use, distribution and reproduction in any medium, provided the work is properly cited. 